D.L. McKenzie

W.T. Collard

K.G. Rice

\section{Comparative gene transfer efficiency of low molecular weight polylysine DNA- condensing peptides}

Key words: DNA condensate; gene delivery; gene therapy; polylysine

Donald L. McKenzie, Wendy T. Collard and Kevin G. Rice, Divisions of Medicinal Chemistry and Pharmaceutics, College of Pharmacy, University of Michigan, Ann Arbor, USA.

\section{Correspondence to:}

Kevin G. Rice

Divisions of Medicinal Chemistry and

Pharmaceutics

College of Pharmacy

University of Michigan

Ann Arbor

MI 48109-1065

USA

Tel: $1-734-763-1032$

Fax: 1-734-763-2022

E-mail: krice@umich.edu

Dates:

Received 3 November 1998

Revised 11 January 1999

Accepted 14 March 1999

To cite this article:

McKenzie, D.L., Collard, W.T. ↔) Rice, K.G. Comparative gene transfer efficiency of low molecular weight

polylysine DNA-condensing peptides.

J. Peptide Res., 1999, 54, 311-318.

Copyright Munksgaard International Publishers Ltd, 1999 ISSN $1397-002 \mathrm{X}$
Abstract: In a previous report (M.S. Wadhwa et al. (1997) Bioconjugate Chem. 8, 81-88), we synthesized a panel of polylysine-containing peptides and determined that a minimal repeating lysine chain of 18 residues followed by a tryptophan and an alkylated cysteine residue $\left(\mathrm{AlkCWK}_{18}\right)$ resulted in the formation of optimal size (78 $\mathrm{nm}$ diameter) plasmid DNA condensates that mediated efficient in vitro gene transfer. Shorter polylysine chains produced larger DNA condensates and mediated much lower gene expression while longer lysine chains were equivalent to AlkCWK ${ }_{18}$. Surprisingly, AlkCWK ${ }_{18}$ (molecular weight 2672) was a much better gene transfer agent than commercially available low molecular weight polylysine (molecular weight 1000-4000), despite its similar molecular weight. Possible explanations were that the cysteine or tryptophan residue in $\mathrm{AlkCWK}_{18}$ contributed to the DNA binding and the formation of small condensates or that the homogeneity of $\mathrm{AlkCWK}_{18}$ relative to low molecular weight polylysine facilitated optimal condensation. To test these hypotheses, the present study prepared $\mathrm{AlkCYK}_{18}$ and $\mathrm{K}_{20}$ and used these to form DNA condensates and conduct in vitro gene transfer. The results established that DNA condensates prepared with either $\mathrm{AlkCYK}_{18}$ or $\mathrm{K}_{20}$ possessed identical particle size and mediated in vitro gene transfer efficiencies that were indistinguishable from AlkCWK ${ }_{18}$ DNA condensates, eliminating the possibility of contributions from cysteine or tryptophan. However, a detailed chromatographic and electrospray mass spectrometry analysis of low molecular weight polylysine revealed it to possess a much lower than anticipated average chain length of $d p$. Thus, the short chain length of low molecular weight polylysine explains its inability to form small DNA condensates and mediate efficient gene transfer relative to 
AlkCWK $_{18}$ DNA condensates. These experiments further emphasize the need to develop homogenous low molecular weight carrier molecules for nonviral gene delivery.

Abbreviations: DIC, diisopropylcarbodiimide; DTT, dithiothreitol; EDT, ethanedithiol; ES-MS, electrospray mass spectrometry; FBS, fetal bovine serum; HBM, Hepes-buffered mannitol; HOBt, 9-hydroxybenzotriazole; HPLC, high-performance liquid chromatography; LB, Lurai-Bertani; LMW, low molecular weight; MEM, minimal essential media; MW, molecular weight; NMR, nuclear magnetic resonance; RLU, relative light units; SFM, serum-free media; TFA, trifluoroacetic acid.

\section{Introduction}

A variety of nonviral gene transfer agents have been developed as carriers that mediate the in vitro and in vivo transfer of foreign DNA. These generally fall into the three categories of cationic lipids (1), synthetic polymers (including dendrimers, polyethylenimine and peptiods) $(2-5)$ and peptides (6-8).

Among the peptides studied as gene delivery agents, polylysine has been shown to bind electrostatically to DNA and form condensates in which the peptide length influences particle size and the resulting gene transfer efficiency $(9,10)$. One study found that condensed DNA particle size decreased with decreasing polylysine chain length such that $4 \mathrm{kDa}$ polylysine produced 20-30 nm DNA condensates whereas $224 \mathrm{kDa}$ polylysine resulted in 120-300 nm DNA condensates (9). A more recent study reported that $27 \mathrm{kDa}$ polylysine forms $2-\mu \mathrm{m}$ diameter particles that are poor mediators of gene transfer relative to other cationic polymers (10).

A further complication arises during the covalent attachment of effector molecules to polylysine, such as carbohydrates, proteins or polyethylene glycol, to prepare DNA carrier molecules capable of achieving cell type selective targeting (11-15). The chemical derivatization of polydisperse polylysine further increases the heterogeneity of these carrier molecules, contributing to the variable performance of the resulting DNA carrier formulation (16). Consequently, homogenous peptide carriers have the advantage of precise chemical control during the synthesis of conjugates and formulation with plasmid DNA resulting in greater reproducibility during in vitro and in vivo gene transfer.

We have previously synthesized DNA-condensing peptides composed of cysteine, tryptophan and 3-36 residues of lysine in an attempt to define the minimal polylysine chain length needed to mediate efficient gene transfer (17). According to this design, the cysteine residue served as a specific functional group for ligand attachment and the tryptophan afforded a hydrophobic chromophore to aid in high-performance liquid chromatography (HPLC) purification. Detailed analysis of these peptides established that a continuous sequence of 18 lysines was sufficient to condense plasmid DNA into $78 \mathrm{~nm}$ particles, whereas shorter polylysine chains exhibited weaker affinity and resulted in larger (200-2000 $\mathrm{nm}$ ) DNA condensates which were inferior in mediating in vitro gene expression (17). During the course of this study, we found that commercially available low molecular weight (LMW) polylysine (1000$4000 \mathrm{Da})$ formed much larger condensates and failed to mediate significant gene expression. It was suggested that, in addition to polylysine chain length, the insertion of an aromatic amino acid may contribute to the DNA-binding affinity and the formation of small condensates through intercalation.

Several studies have previously observed enhanced peptide binding to DNA through intercalation of aromatic amino acid residues (18-20). NMR experiments demonstrated that a synthetic peptide (YSPTSPSY) positioned two tyrosine residues to simultaneously intercalate with DNA to enhance its binding affinity (18). Likewise, the chirality and position of an aromatic amino acid within a peptide was also found to influence the intercalation and the binding affinity to DNA (19). Furthermore, the number of aromatic amino acids correlated with the degree of intercalation into DNA such that peptides containing $>30 \%$ aromatic amino acids had higher affinity for DNA than polylysine (20).

In the present study we correlated the relative DNAbinding affinity, particle size and the resulting gene transfer efficiency for several homogenous peptides with and without aromatic residues. The results rationalize our earlier observations on LMW polylysine and help to further establish the optimal size and composition of DNAcondensing peptides for nonviral gene delivery.

\section{Experimental Procedures}

N-terminal Fmoc-protected amino acids, and all other reagents for peptide synthesis, were obtained from Advanced ChemTech (Lexington, KY, USA). Minimum essential media (MEM), dithiothreitol (DTT), iodoacetic acid and

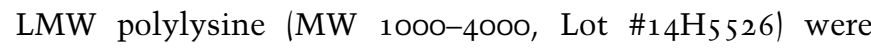
purchased from Sigma Chemical Co. (St. Louis, MO, USA). Ethanedithiol (EDT) and N,N-dimethylformamide were 
purchased from Aldrich Chemical Co. (Milwaukee, WI, USA). Trifluoroacetic acid (TFA) was purchased from Fisher Scientific (Pittsburgh, PA, USA). Luria-Bertani (LB) media, LB agar, D-luciferin and luciferase from Photinus pyralis (EC1.13.12.7) were obtained from Boehringer-Mannheim (Indianapolis, IN, USA). HepG2 cells were from the American Type Culture Collection (Rockville, MD, USA). Inactivated 'qualified' fetal bovine serum (FBS) were from Gibco BRL (Grand Island, NY, USA). Bradford reagent was purchased from Bio-Rad (Hercules, CA, USA) and thiazole orange was a gift from Beckton-Dickinson Immunocytometry Systems (San Jose, CA, USA). The $5.6 \mathrm{~kb}$ plasmid pCMLV encoding the reporter gene luciferase under the control of the cytomegalovirus promoter was a gift from Dr M. A. Hickman at the University of California, Davis (21). Peptide synthesis was performed on a computer-interfaced Model 90 Advanced ChemTech solid-phase peptide synthesizer (Lexington, KY, USA). Peptide purification was performed using a semipreparative $(10 \mu \mathrm{m}) \mathrm{C}_{18}$ reverse phase (RP)-HPLC column and cation exchange chromatography was performed using an analytical $(5 \mu \mathrm{m})$ 400VHP575 cationic exchange column from Vydac (Hesperia, CA, USA). HPLC was performed using a computer-interfaced HPLC and fraction collector from ISCO (Lincoln, NE, USA).

\section{Peptide synthesis and characterization}

$\mathrm{CWK}_{18}, \mathrm{CYK}_{18}$ and $\mathrm{K}_{2 \mathrm{O}}$ were synthesized using standard Fmoc procedures with 9-hydroxybenzotriazole (HOBt) and diisopropylcarbodiimide (DIC) couplings followed by $\mathrm{N}$ capping with acetic anhydride after each round of coupling. The $\mathrm{N}$-terminal Fmoc group was purposely left on $\mathrm{K}_{2 \mathrm{O}}$ at the completion of the synthesis to enhance purification (22). Peptides were cleaved from the resin and side-chain protecting groups were removed by $1 \mathrm{~h}$ reaction with TFA : EDT : water $(95: 2.5: 2.5 \mathrm{v} / \mathrm{v} / \mathrm{v})$ for the cysteinecontaining peptides and TFA : water $(95: 5 \mathrm{v} / \mathrm{v})$ for $\mathrm{K}_{20}$. $\mathrm{CWK}_{18}$ was purified as described previously (17). CYK 18 was purified by injecting $3 \mu \mathrm{mol}$ onto a Vydac $\mathrm{C}_{18} \mathrm{RP}-\mathrm{HPLC}$ column $(2 \times 25 \mathrm{~cm})$ eluted at $10 \mathrm{~mL} / \mathrm{min}$ with $0.1 \%$ TFA and a gradient of $5-20 \%$ acetonitrile over $30 \mathrm{~min}$ while monitoring absorbance at $274 \mathrm{~nm}$. The major peptide peak eluting at $21 \mathrm{~min}$ was collected and pooled from multiple runs, concentrated by rotary evaporation, lyophilized and stored dry at $-20^{\circ} \mathrm{C}$. The purified peptide was dissolved in $0.1 \%$ TFA (degassed with $\mathrm{N}_{2}$ ) and quantified by absorbance $\left(\mathrm{CYK}_{18} ; \varepsilon_{280 n m}=1330 \mathrm{M}^{-1} / \mathrm{cm}\right)$ to determine the isolated yield which was typically $40 \%$.
$\mathrm{CWK}_{18}$ and $\mathrm{CYK}_{18}$ were alkylated with iodoacetic acid by adding $50 \mu \mathrm{mol}$ of dithiothreitol and $250 \mu \mathrm{mol}$ of iodoacetic acid to $2.5 \mu \mathrm{mol}$ of peptide in $1.5 \mathrm{~mL}$ of $50 \mathrm{~mm}$ Tris $(\mathrm{pH} 7.5)$ buffer and reacted at room temperature for $1 \mathrm{~h}$. Each alkylated peptide was purified on RP-HPLC resulting in $>95 \%$ purity and then analyzed by electrospray mass spectroscopy (ES-MS) by infusing a $5-\mathrm{nmol} / \mathrm{mL}$ solution of peptide prepared in $50: 46: 4 \%(\mathrm{v} / \mathrm{v})$ acetonitrile : water : acetic acid into the source of a VG (Micromass) Platform single quadrapole mass spectrometer $(0-3000 \mathrm{~m} / \mathrm{z})$ operated in the positive ion mode. A mass of $2671.4^{\mathrm{obs}} / 2670.8^{\text {calc }}$ and $2650.1^{\mathrm{obs}} / 2649.5^{\text {calc }}$ was determined for (alkylated) $\mathrm{AlkCWK}_{18}$ and (alkylated) AlkCYK ${ }_{18}$, respectively.

Fmoc- $\mathrm{K}_{2 \mathrm{O}}$ was purified by injecting $3 \mu \mathrm{mol}$ onto a semipreparative Vydac $\mathrm{C}_{18}$ RP-HPLC column $(2 \times 25 \mathrm{~cm})$ eluted isocratically at $10 \mathrm{~mL} / \mathrm{min}$ with $16 \%$ acetonitrile while detecting by absorbance at $260 \mathrm{~nm}$. The product peak eluting at 23 min was collected and concentrated to dryness. The N-terminal Fmoc was removed by reacting the peptide with $5 \% \mathrm{v} / \mathrm{v}$ triethylamine for $6 \mathrm{~h}$ at room temperature (22). Following ether extraction, the peptide was purified to homogeneity on preparative HPLC by injecting $3 \mu \mathrm{mol}$ onto a semipreparative RP-HPLC column eluting isocratically at $10 \mathrm{~mL} / \mathrm{min}$ with $0.05 \%$ TFA and $5 \%$ acetonitrile while monitoring absorbance at $214 \mathrm{~nm}$. The product peak eluting at $22 \mathrm{~min}$ was pooled from multiple runs, dried and dissolved in $0.1 \%$ TFA. The purity of $\mathrm{K}_{2 \mathrm{O}}$ was also > $95 \%$ as determined from cation exchange HPLC analysis as described below. The concentration of $\mathrm{a}_{2 \mathrm{O}}$ stock solution was determined by fluorescamine analysis (23) using $\mathrm{AlkCWK}_{18}$ as a primary standard which determined the yield of $\mathrm{K}_{2 \mathrm{O}}$ from the synthesis to be $69 \%$. The mass of $\mathrm{K}_{2 \mathrm{O}}$ was determined to be $2583.0^{\text {obs }} / 2581.4^{\text {calc }}$ by ES-MS as described above.

The concentration of a stock solution of LMW polylysine (1000-4000, $\mathrm{HBr}$ salt form) was also established using $\mathrm{AlkCWK}_{18}$ as a calibrator for fluorescamine analysis. LMW polylysine was analyzed by injecting $12 \mathrm{nmol}$ onto a cation-exchange column (Vydac $400 \mathrm{~V} \mathrm{HP} 575$ ) eluted at $1 \mathrm{~mL} / \mathrm{min}$ with a sodium chloride gradient of 0.1-1.5 M over 30 min while detecting the eluting peaks by absorbance at $214 \mathrm{~nm}$. The chromatographic drift resulting from gradient elution was corrected by subtracting a blank.

\section{DNA condensation and gene expression}

Peptide DNA condensates were prepared at a final DNA concentration of $20 \mu \mathrm{g} / \mathrm{mL}$ and at a peptide/DNA stoichiometry varying from 0.1 to $1.5 \mathrm{nmol}$ of peptide per $\mu \mathrm{g}$ of DNA 
(0.5: 1 to $8: 1$ amine : phosphate ratio). The condensates were formed by adding peptide $(2-30 \mathrm{nmol})$ prepared in $500 \mu \mathrm{L}$ of isotonic Hepes-buffered mannitol (HBM, 0.27 M mannitol, $5 \mathrm{~mm}$ sodium Hepes, $\mathrm{pH} 7.5)$ to $20 \mu \mathrm{g}$ of DNA in $500 \mu \mathrm{L}$ HBM while vortexing, followed by equilibration at room temperature for $30 \mathrm{~min}$.

Peptide binding to DNA was monitored by a fluorescence titration assay (24). A $1-\mu$ g aliquot of the peptide DNA condensate was diluted to $1 \mathrm{~mL}$ in $\mathrm{HBM}$ containing $0.1 \mu \mathrm{M}$ thiazole orange. The fluorescence of the intercalated dye was measured on an LS 5 oB fluorimeter (Perkin-Elmer, UK) in a microcuvette by exciting at $500 \mathrm{~nm}$ while monitoring emission at $530 \mathrm{~nm}$, with the slits set at 15 and $20 \mathrm{~nm}$ and photomultiplier gain set to $700 \mathrm{~V}$. DNA condensation was monitored by measuring total scattered light at $90^{\circ}$ by setting both monochromators to $450 \mathrm{~nm}$ and decreasing slit widths to $2.5 \mathrm{~nm}$. Fluorescence and scattered light intensity blanks were subtracted from all values before data analysis.

Particle size analysis was measured for peptide DNA condensates prepared at a DNA concentration of $20 \mu \mathrm{g} / \mathrm{mL}$ in HBM and at a stoichiometry of $0.8 \mathrm{nmol}$ of peptide per $\mu \mathrm{g}$ of DNA (5.5: 1 amine : phosphate). Samples were analyzed using a Brookhaven ZetaPlus quasielastic light-scattering particle sizer. The mean diameter and population distribution were computed from the diffusion coefficient using functions supplied by the instrument.

HepG 2 cells $\left(2 \times 10^{6}\right.$ cells $)$ were plated on $6 \times 35 \mathrm{~mm}$ wells and grown to $40-70 \%$ confluency in MEM supplemented with $10 \%$ FBS, penicillin and streptomycin (10 ooo $\mathrm{U} / \mathrm{mL}$ ), sodium pyruvate $(100 \mathrm{mM}$ ) and L-glutamine (200 mM). Transfections were performed in MEM ( $2 \mathrm{~mL}$ per $35 \mathrm{~mm}$ well) with $2 \%$ FBS, with $80 \mu \mathrm{M}$ chloroquine (25). Peptide DNA condensates (10 $\mu$ g of DNA in $0.5 \mathrm{~mL} \mathrm{HBM)}$ were added dropwise to triplicate wells. After $5 \mathrm{~h}$ incubation at $37^{\circ} \mathrm{C}$, the media was replaced with MEM supplemented with $10 \%$ FBS.

Luciferase expression was determined at $24 \mathrm{~h}$ using some modification of a published method (26). Cells were washed twice with ice-cold phosphate-buffered saline (calcium and magnesium free) and then treated with $0.5 \mathrm{~mL}$ of ice-cold lysis buffer $(25 \mathrm{~mm}$ Tris chloride $\mathrm{pH} 7.8,1 \mathrm{~mm}$ EDTA, $8 \mathrm{~mm}$ magnesium chloride, $1 \%$ Triton X-100, $1 \mathrm{~mm}$ DTT) for $10 \mathrm{~min}$. The cell lysate was scraped, transferred to 1.5 $\mathrm{mL}$ micro-centrifuge tubes and centrifuged for $7 \mathrm{~min}$ at 13 ooo $\mathrm{g}$ at $4{ }^{\circ} \mathrm{C}$ to pellet debris.

Lysis buffer $(300 \mu \mathrm{L})$, sodium-ATP $(4 \mu \mathrm{L}$ of a $180-\mathrm{mm}$ solution, $\left.\mathrm{pH} 7,4^{\circ} \mathrm{C}\right)$ and cell lysate $\left(100 \mu \mathrm{L}, 4^{\circ} \mathrm{C}\right)$ were combined in a test tube, briefly mixed and immediately placed in the luminometer. Luciferase relative light units
(RLU) were recorded on a Lumat LB 9501 (Berthold Systems, Germany) with $10 \mathrm{~s}$ integration after automatic injection of $100 \mu \mathrm{L}$ of $0.5 \mathrm{~mm}$ D-luciferin (prepared fresh in lysis buffer without DTT). The RLU were converted into fmol using a standard curve generated by adding a known amount of the luciferase (0.01-100 fmol with specific activity of $2.5 \mathrm{nU} /$ fmol) to $35 \mathrm{~mm}$ wells containing $40-70 \%$ confluent HepG2 cells. The cells were processed as described above resulting in a standard curve with an average slope of 220 ooo RLU/ fmol of enzyme. Protein concentrations were measured by Bradford assay using bovine serum albumin as a standard (27). The amount of luciferase recovered in each sample was normalized to milligrams of protein and the mean and standard deviation obtained from each triplicate are reported.

LipofectAce $^{(\mathrm{m})}$ /Gibco BRL, $1: 2.5$ w/w dimethyl dioctadecylammonium bromide and dioleoyl phosphatidylethanolamine) was used to mediate gene transfection according to the manufacturer's instructions. The ratio of DNA to lipofectAce was optimized for HepG2 cells. An optimal DNA/lipofectAce ratio was achieved by dissolving $10 \mu \mathrm{g}$ of DNA in $100 \mu \mathrm{L}$ of serum-free media (SFM) followed by adding $60 \mu \mathrm{L}$ of lipofectAce prepared in $140 \mu \mathrm{L}$ of SFM. The LipofectAce-DNA complex was then diluted with $1.7 \mathrm{~mL}$ of SFM and used to transfect HepG2 cells for $5 \mathrm{~h}$ followed by replacing the transfecting media with supplemented $10 \%$ FBS. The cells were incubated for a total of $24 \mathrm{~h}$ then harvested and analyzed for luciferase as described above.

\section{Results and Discussion}

Solid-phase synthesis of polylysine-containing peptides is complicated by poor yields arising from the repeating sequence and by difficulty in purification of the desired full-length peptide. These problems can be minimized through double coupling, end-capping, and by positioning a hydrophobic aromatic amino acid near the $\mathrm{N}$-terminus to allow peak identification on RP-HPLC, strategies that proved successful in the synthesis of $\mathrm{CWK}_{18}$.

Consequently, substitution of tryptophan with tyrosine to prepare $\mathrm{CYK}_{18}$ (Fig. 1) was of no greater synthetic challenge than the synthesis of $\mathrm{CWK}_{18}$ and was viewed as a first step toward determining whether tryptophan enhanced the binding of $\mathrm{CWK}_{18}$ to DNA. A difference in the DNA intercalation of aromatic residue in $\mathrm{AlkCYK}_{18}$ and AlkCWK $_{18}$ could lead to differences in binding affinity and the resulting DNA condensate particle size. However, a detailed comparison of the fluorescence quench and total 

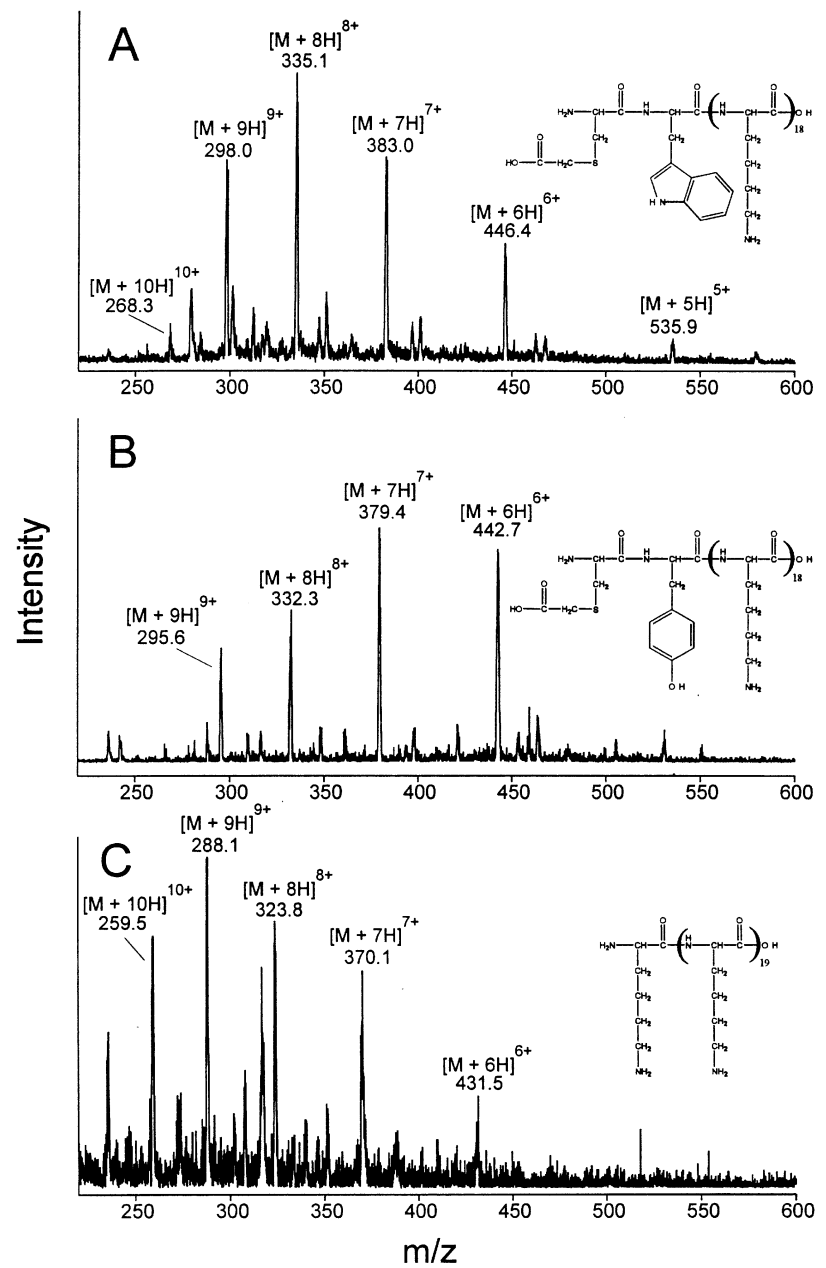

Figure 1. Structure of polylysine peptides used for gene delivery. The structure and ES-MS analysis for $\mathrm{AlkCWK}_{18}, \mathrm{AlkCYK}_{18}$ and $\mathrm{K}_{2 \mathrm{O}}$ are compared. Each peptide was detected as the $[\mathrm{M}+6 \mathrm{H}]^{6+}-\left[\mathrm{M}+{ }_{9} \mathrm{H}\right]^{9+}$ charge state.

light-scattering titration curves for $\mathrm{AlkCWK}_{18}$ and $\mathrm{AlkCYK}_{18}$ indicated no significant difference in their binding to DNA (Fig. 2A, B). Each peptide fully displaced the intercalating dye at a $1.1: 1$ amine : phosphate ratio. The light-scattering profiles established that each condensate was fully formed at stoichiometries above a $2.5: 1$ amine : phosphate ratio. Likewise, QELS analysis of $\mathrm{AlkCWK}_{18}$ and $\mathrm{AlkCYK}_{18}$ DNA condensates indicated that each formed a major (>95\%) population of particles with a mean diameter of $43 \mathrm{~nm}$ (Fig. $2 \mathrm{~A}^{\prime}, \mathrm{B}^{\prime}$ ). Thus, the physical properties of $\mathrm{AlkCWK}_{18}$ and $\mathrm{AlkCYK}_{18}$ DNA condensates were indistinguishable.

$\mathrm{AlkCWK}_{18}$ and $\mathrm{AlkCYK}_{18}$ DNA condensates were also compared for in vitro gene transfer in HepG2 cells. Both mediated essentially equivalent levels of gene expression in the presence of chloroquine and serum which was slightly higher than that mediated by LipofectAce in the absence of chloroquine and serum (Fig. 3). These results suggested that

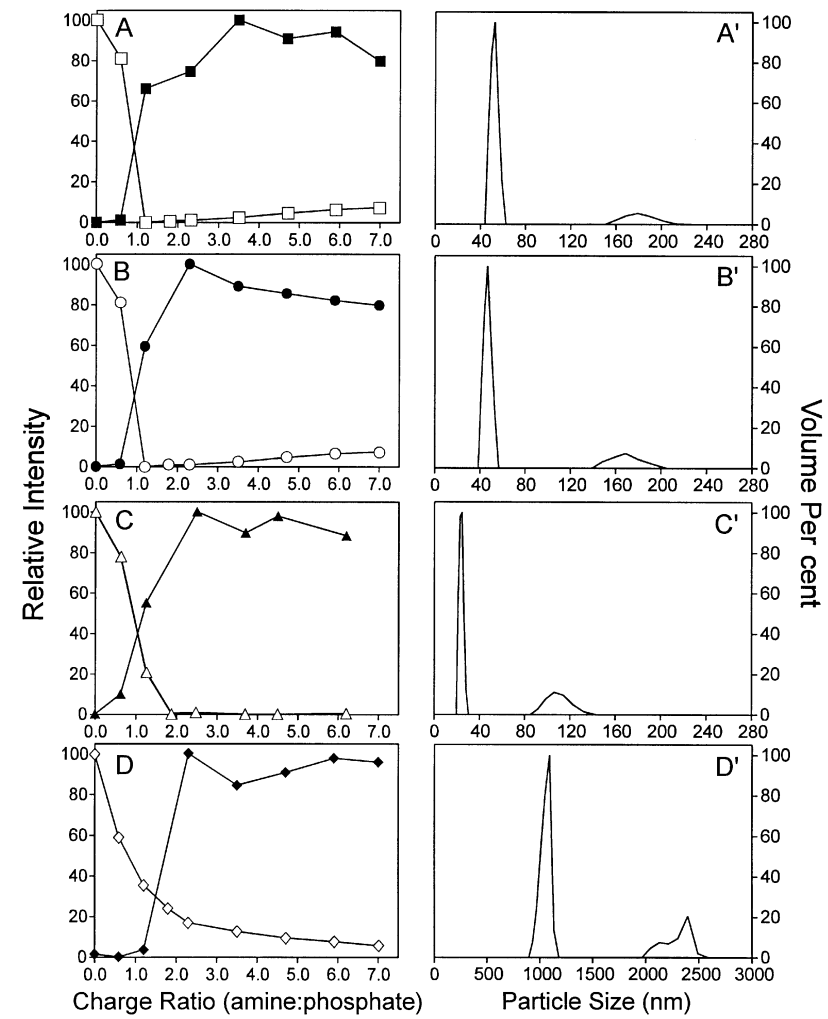

Figure 2. Analysis of DNA condensation with polylysine peptides. The thiazole orange fluorescence intensity (open symbol) is plotted along with the total light scattering (closed symbol) for the titration of DNA with $\mathrm{AlkCWK}_{18}$ (A), AlkCYK $\mathrm{Al}_{18}(\mathrm{~B}) \mathrm{K}_{20}$ (C) and LMW polylysine (D). The QELS particle size analysis for DNA peptide condensates prepared at a concentration of $0.8 \mathrm{nmol}$ of peptide per $\mu \mathrm{g}$ of DNA (charge ratio $\approx 5.5: 1)$ is shown for $\operatorname{AlkCWK}_{18}\left(\mathrm{~A}^{\prime}\right), \mathrm{AlkCYK}_{18}\left(\mathrm{~B}^{\prime}\right) \mathrm{K}_{20}\left(\mathrm{C}^{\prime}\right)$ and $\mathrm{LMW}$ polylysine $\left(\mathrm{D}^{\prime}\right)$.

either the aromatic residue in $\mathrm{AlkCWK}_{18}$ and $\mathrm{AlkCYK}_{18}$ function equivalently or that these residues do not significantly influence peptide binding, condensation and gene transfer efficiency of DNA.

The further comparison of the properties of homogenous polylysine DNA-condensing peptides required the removal of the aromatic residue to prepare $\mathrm{K}_{20}$. However, this complicated the isolation of the full-length peptide due to the lack of hydrophobic chromophore during HPLC purification. Consequently, this obstacle was overcome while synthesizing $\mathrm{K}_{2}$ by retaining Fmoc on the $\mathrm{N}$-terminus during the final cycle of synthesis, thereby using it as removable chromophore following RP-HPLC purification.

Comparison of the fluorescence and total light-scattering titration for $\mathrm{K}_{20}$ and commercially available LMW polylysine established that $K_{20}$ completely quenched the fluorescence at an amine: phosphate ratio of $\approx 2: 1$, while LMW polylysine bound to DNA over a broader range and only reached an equivalent point at an amine : phosphate ratio of $\approx 4: 1$ (Fig. $2 \mathrm{C}, \mathrm{D}$ ). In contrast, the total 


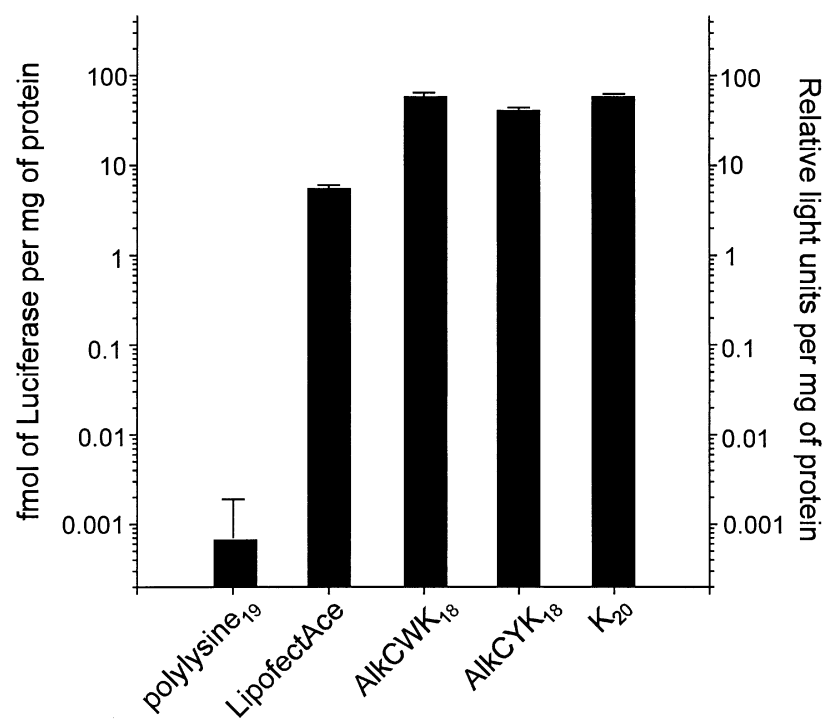

Figure 3. Gene transfer efficiency of peptide DNA condensates. The gene transfer efficiency, as determined by luciferase expression in HepG2 cells, is compared for peptide DNA condensates prepared at $0.8 \mathrm{nmol}$ of peptide per $\mu \mathrm{g}$ of DNA (charge ratio of $\approx 5.5: 1$ ) for the peptides indicated. LipofectAce transfection is included for comparison.

light-scattering profile for $\mathrm{K}_{20}$ and LMW polylysine indicated that each formed fully condensed DNA at an amine : phosphate ratio above $3: 1$.

The most significant difference between $\mathrm{K}_{20}$ and LMW polylysine was the particle size of their DNA condensates. $\mathrm{K}_{20}$ formed small DNA condensates of $\approx 32 \mathrm{~nm}$ diameter (Fig. $2 \mathrm{C}^{\prime}$ ) which were comparable with those formed by $\mathrm{AlkCWK}_{18}$ and $\mathrm{AlkCYK}_{18}$ (Fig. 2A', B'), whereas LMW polylysine formed large DNA condensates that were $>1 \mu \mathrm{m}$ in diameter (Fig. $\left.2 \mathrm{D}^{\prime}\right)$.

$\mathrm{K}_{2 \mathrm{O}}$ and LMW polylysine DNA condensates were also compared for their ability to transform cells in vitro. LMW polylysine demonstrated a four-order of magnitude decrease in mediating gene transfer in HepG2 cells relative to $\mathrm{K}_{2 \mathrm{O}}$ which was equivalent to the gene transfer efficiency mediated by $\mathrm{AlkCWK}_{18}$ and $\mathrm{AlkCYK}_{18}$ (Fig. 3). From these results, we concluded that differences in amino acid composition cannot account for the gene transfer properties of $\mathrm{AlkCWK}_{18}, \mathrm{AlkCYK}_{18}$ and $\mathrm{K}_{20}$ relative to LMW polylysine.

ES-MS molecular weight analysis provided definitive proof of the structure of $\mathrm{AlkCWK}_{18}, \mathrm{AlkCYK}_{18}$ and $\mathrm{K}_{2 \mathrm{O}}$ (Fig. 1) but proved unsuccessful for characterizing the mass of LMW polylysine. Therefore, cation-exchange chromatography was used to separate LMW polylysine into its component peptides (Fig. 4A). Coelution of $\mathrm{K}_{20}$ with LMW polylysine not only established the polydispersity of the later, but also revealed its average molecular weight to be significantly lower than dp 20, since polylysines are retained
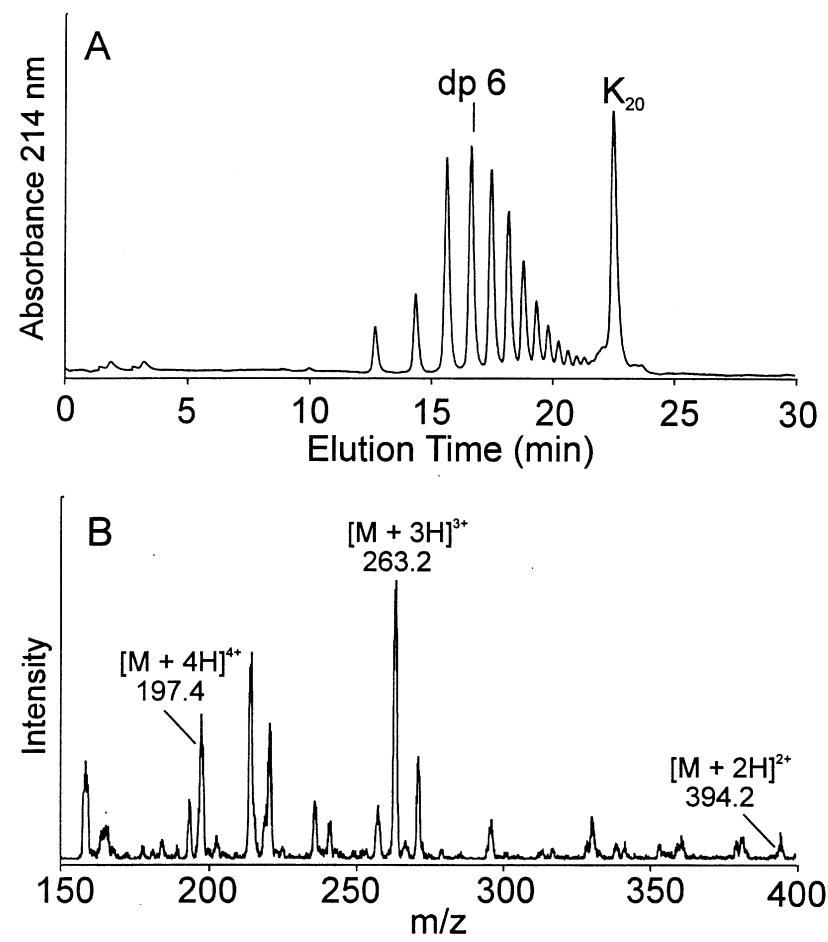

Figure 4. Cation-exchange HPLC and ES-MS analysis of LMW polylysine. The polydispersity of LMW polylysine was determined using cation-exchange HPLC, which includes a spiked sample of $\mathrm{K}_{2 \mathrm{O}}$ as indicated in (A). ES-MS analysis of the major LMW polylysine peak established it as dp 6 as illustrated in (B). The results confirmed an average chain length of 6 for LMW polylysine.

according to their number of cationic charges. This was confirmed by isolating the major LMW polylysine peptide which produced an ES-MS mass of 786.5 confirming it as dp 6 (Fig. 4B). A 10\% impurity of dp 6 produced an ion $\left[\mathrm{M}+{ }_{3} \mathrm{H}\right]^{3^{+}}$at $\mathrm{m} / \mathrm{z}$ of 220.3 predicting a mass of 658.2 corresponding to dp 5 . Since the molar absorptivity of each polylysine peptide is dependent on the number of lysine residues, the cation-exchange chromatograph represents a weight average distribution analysis of the polypeptide mixture. Thereby, dp 5, 6 and 7 are the major peptides based both on a weight and mol basis.

The conclusion drawn from this study is that a peptide of $\approx 18$ lysines is sufficient to condense DNA into small particles that mediate efficient gene transfer in the presence of chloroquine. It appears that a single aromatic amino acid does not play a significant role in the ability of $\mathrm{AlkCWK}_{18}$ and $\mathrm{AlkCYK}_{18}$ to bind and condense DNA. However, LMW polylysine does not adequately substitute for $\mathrm{AlkCWk}_{18}$, AlkCYK $_{18}$ or $\mathrm{K}_{20}$ because it possesses significant heterogeneity and has a mean size distribution weighted towards lower molecular weight polylysine chains which condense DNA to form large particles. This is consistent with our previous results, which demonstrated that LMW polylysine 
peptides (degree of polymerization (dp) 10) condense DNA, but form large particles that are $>1 \mu \mathrm{m}$ in size (17).

The size of DNA condensates appears to be directly correlated to the gene transfer efficiency. However, an alternative explanation is that the relative serum stability of the condensed DNA also correlates with the gene transfer efficiency. We have recently reported that weak binding peptides possessing eight lysine residues $\left(\mathrm{AlkCWK}_{8}\right)$ dissociate from DNA at sodium chloride concentrations below $0.15 \mathrm{M}$ (normal saline) and fail to protect DNA from endonuclease attack in serum (28). Thus, the inefficient gene transfer mediated by DNA condensates prepared with LMW polylysine could also be due to premature metabolism of the DNA in the cell culture media during in vitro transfection. Consequently, $\mathrm{AlkCWK}_{18}$ is a homogenous peptide that produces both small condensates and protects DNA from degradation in serum (26). These are important attributes towards the development of homogenous nonviral gene delivery agents. Future studies will demonstrate the utility of functionalizing the cysteine residue with targeting ligands to create homogenous LMW carrier molecules for gene delivery.

Acknowledgments: The authors acknowledge financial support from NIH GM48409 and Liu Guo for help in the synthesis of $\mathrm{CYK}_{18}$.

\section{References}

1. Ledley, F.D. (1995) Nonviral gene therapy: The promise of genes as pharmaceutical products. Hum. Gene Ther. 6, 1129-1144.

2. Tang, M.X., Redemann, C.T. \& Szoka, F.C. Jr (1996) In vitro gene delivery by degraded polyamidoamine dendrimers. Bioconjugate Chem. 7, 703-714.

3. Haensler, J. \& Szoka, F.C. Jr (1993) Polyamidoamine cascade polymers mediate efficient transfection of cells in culture. Bioconjugate Chem. 4, 372-379.

4. Boussif, O., Zanta, M.A. \& Behr, J.-P. (1996) Optimized galenics improve in vitro gene transfer with cationic molecules up to 100o-fold. Gene Ther. 3, 1074-1080.

5. Murphy, J.E., Uno, T., Hamer, J.D., Cohen, F.E., Dwarki, V. \& Zuckermann, R.N. (1998) A combinatorial approach to the discovery of efficient cationic peptoid reagents for gene delivery. Proc. Natl Acad. Sci. USA 95, 15171522.

6. Niidome, T., Ohmori, N., Ichinose, A., Wada, A., Mihara, H., Toshiya, H. \& Haruhiko, A. (1997) Binding of cationic $\alpha$-helical peptides to plasmid DNA and their gene transfer abilities into cells. J. Biol. Chem. 272, 1530715312.

7. Morris, M.C., Vidal, P., Chaloin, L., Heitz, F. \& Divita, G. (1997) A new peptide vector for efficient delivery of oligonucleotides into mammalian cells. Nucleic Acids Res. 25, 2730-2736.

8. Erbacher, P., Roche, A.C., Monsigny, M. \& Midoux, P. (1995) Glycosylated polylysine/ DNA complexes: gene transfer efficiency in relation with the size and the sugar substitution level of glycosylated polylysines and with the plasmid size. Bioconjugate Chem. 6, 401-410.
9. Wolfert, M.A. \& Seymour, L.W. (1996) Atomic force microscopic analysis of the influence of the molecular weight of poly $(\mathrm{L})$ lysine on the size of polyelectrolyte complexes formed with DNA. Gene Ther. 3, 269-273.

10. Tang, M.X. \& Szoka, F.C. Jr (1997) The influence of polymer structure on the interactions of cationic polymers with DNA and morphology of the resulting complexes. Gene Ther. 4, 823-832.

11. Wu, G.Y. \& Wu, C.Y. (1988) Receptormediated gene delivery and expression in vivo. J. Biol. Chem. 29, 14621-14624.

12. Midoux, P., Mendes, C., Legrand, A., Raimond, J., Mayer, R., Monsigny, M. \& Roche, C. (1993) Specific gene transfer mediated by lactosylated poly-L-lysine into hepatoma cells. Nucleic Acids Res. 21, $871-$ 878

13. Merwin, J.R., Noell, G.S., Thomas, W.L., Chiou, H.C., DeRome, M.E., McKee, T.D., Spitalny, G.L. \& Findeis, M.A. (1994) Targeted delivery of DNA using YEE (GalNAcAH) 3, a synthetic glycopeptide ligand for the asialoglycoprotein receptor. Bioconjugate Chem. 5, 612-620.

14. Katayose, S. \& Kataoka, K. (1997) Watersoluble polyion complex associates of DNA and poly (ethylene glycol)-poly (L-lysine). Block Copolymers 8, 702-707.

15. Toncheva, V., Wolfert, M.A., Dash, P.R., Oupicky, D., Ulbrich, K., Seymour, L.W. \& Schacht, E.H. (1998) Novel vectors for gene delivery formed by self-assembly of DNA with poly (L-) lysine grafted with hydrophilic polymers. Biochim. Biophys. Acta 1380, 354368 .
16. McKee, T.D., DeRome, M.E., Wu, G.Y. \& Findeis, M.A. (1994) Preparation of asialoorosomucoid-polylysine conjugates. Bioconjugate Chem. 5, 306-311.

17. Wadhwa, M.S., Collard, W.T., Adami, R.C., McKenzie, D.L. \& Rice, K.G. (1997) Peptide mediated gene delivery: influence of peptide structure on gene expression. Bioconjugate Chem. 8, 81-88.

18. Harding, M.M. (1992) NMR studies on YSPTSPSY: implications for the design of DNA bisintercalators. J. Med. Chem. 35, 4658-4664.

19. Reich, Z., Ittah, Y., Weinberger, S. \& Minsky, A. (1990) Chiral and structural discrimination in binding of polypeptides with condensed nucleic acid structures. J. Biol. Chem. 10, 5590-5594.

20. Wehling, K., Arfmann, H.A., Selpke, G. \& Wagner, K.G. (1977) Specificity of DNA-basic polypeptide interactions. II. Influence of aromatic amino acid residues investigated with agarose bound lysine copolypeptides. Nucleic Acids Res. 4, 513-522.

21. Plank, C., Zatloukal, K., Cotten, M., Mechtler, K. \& Wagner, E. (1992) Gene transfer into hepatocytes using asialoglycoprotein receptor mediated endocytosis of DNA complexed with an artificial tetraantennary galactose ligand. Bioconjugate Chem. 3, 533-539.

22. Ball, H.L. \& Mascagni, P. (1992) Purification of synthetic peptides using reversible chromatographic probes based on the Fmoc molecule. Int. J. Peptide Protein Res. 40, 370379 .

23. Weigele, M., DeBernardo, S.L., TneGi, J.P. \& LeimGruger, W. (1972) A novel reagent for the fluorometric assay of primary amines. $J$. Am. Chem. Soc. 94, 5927-5928. 
24. Wadhwa, M., Knoell, D.L., Young, A.P. \& Rice, K.G. (1995) Targeted gene delivery with a low molecular weight glycopeptide. Bioconjugate Chem. 6, 283-291.

25. Pouton, C.W. \& Seymour, L.W. (1998) Key issues in non-viral gene delivery. Adv. Drug Deliv. Rev. 34, 3-19.
26. Brasier, A.R., Tate, J.E. \& Harener, J.F. $(1989)$ Optimized use of the firefly luciferase assay as a reporter gene in mammalian cell lines. BioTechniques 7, 1116-1122.

27. Bradford, M.M. (1976) A rapid and sensitive method for the quantitation of microgram quantities of protein utilizing the principle of protein-dye binding. Analyt. Biochem. 72, 248-254.
28. Adami, R.C., Collard, W.T., Gupta, S.A. Kwok, K.Y., Bonadio, S. \& Rice, K.G. (1998) Stability of peptide condensed plasmid DNA formulations. J. Pharmac. Sci. 87, 678-683. 